\title{
Minimal invasive treatments for renal cell carcinoma
}

\author{
Selahattin Çalışkan ${ }^{1}$, Mustafa Sungur ${ }^{2}$
}

Cite this article: Çalışkan S, Sungur M: Minimal Invasive Treatments for Renal Cell Carcinoma. Ann Urol Oncol 2020; 3(2): 89-96. https://doi.org/10.32948/ auo.2020.09.24

\begin{abstract}
Renal cell carcinoma (RCC) is the most common malignancy of the kidney that accounts $85 \%$ of all renal tumors and $2-3 \%$ of all adult malignancies. The etiology of RCC associated with smoking, obesity, anti-hypertensive therapy, coffee and tea, Western diet (high fat and protein and low fruits and vegetables). However, the detection of small renal masses has been increased because of widespread use of sonography, computed tomography and magnetic resonance imaging techniques in recent years, but one-third of the patients with RCC still present with large, locally advanced or metastatic disease. Surgery is the main treatment for renal cell carcinoma and minimal invasive treatments such as laproscopy and robotic approaches is very popular in the world after the widespread use of technological instruments and technology.
\end{abstract}

Key words Renal cell carcinoma, minimal invasive treatments

1. Department of Urology, İstanbul Reyap Hospital, Istanbul, Turkey.

2. Department of Urology, Çorum Erol Olçok Training and Research Hospital, Hitit University, Turkey.

Correspondence: Selahattin Çalışkan (Department of Urology, İstanbul Reyap Hospital, Ostanbul, Turkey; E-mail: dr.selahattincaliskan@gmail.com). 


\section{Introduction}

Altough Renal Cell Carcinoma (RCC) is $2-3 \%$ of all adult solid tumors, has the highest cancer-related mortality rate in urological malignancies and most of the patients are diagnosed with age between 50 and 70 years [1]. RCC is the third most common urological malignancy after the prostate and bladder cancers [2]. The incidence of renal tumors has continuously risen over the last three decades because of more prevalent use of the cross sectional imaging techniques. The incidence rates of RCC increases with a mean of $2-3 \%$ per year in the world. Despite this rising incidence, 5 year survival rate has improved from 50 to $74 \%$ over the last three decades [3]. The factors for survival improvement includes increase in low stage tumors, advanced surgical techniques and improved medical therapies.

\section{Diagnosis and Staging of Kidney Cancer}

The preoperative evaluation of patients with RCC depends on three principal aims: radiological examination of renal mass, determining the stage of disease, and to describe the anatomic details necessary for operative planning. Abdominal ultrasound or color doppler ultrasound is the simplest method for distinguishing between cystic and solid renal masses and is commonly applied in clinical settings. The sensitivity of ultrasound for the detection of RCC is dependent upon the size and location of the lesion. Plain and contrast-enhanced abdominal computed tomography (CT) is the gold standard for the clinical diagnosis and staging of RCC with a sensitivity of ranging from $88 \%$ to $100 \%$. A threephase CT scan; unenhanced scan, a vascular phase scan (for assessing the renal vasculature) and a nephrographic phase scan (the most sensitive for the nature of mass) is considered as the optimal technique. Magnetic resonance imaging (MRI) has many advantages in the differential diagnosis of RCC or hemorrhagic renal cysts and in determining the range of venous tumor thrombus. Chest X-ray at antero-posterior and lateral positions is the common approach for pre-operative examination and postoperative follow-up in RCC patients.

The other important step for choosing modality is staging. Table 1 and Table 2 shows the TNM staging and Anatomic staging system of renal cell carcinoma (RCC) according to the AJCC Cancer Staging Manual TNM Staging System, 8th edition, 2017.

To determine the operational approach and strategy according to the anatomic details 3 scoring systems have been decsribed. The R.E.N.A.L. nephrometry scoring system and the PADUA classification were described in 2009 for standardizing renal

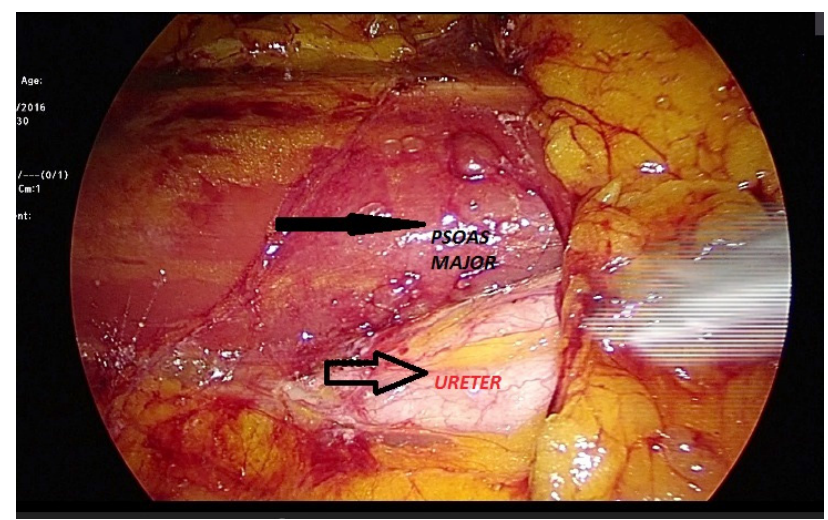

tumor characteristics. The C-index score was reported in 2010 and based on the ratio of the distance between the tumor and kidney center and tumor radius [4]. PADUA score is obtained from longitudinal classification, margin location of tumors, tumor relationship with renal sinus, tumor relationship with urinary collecting system, tumor deepening into the parenchyma and tumor size. According to the sum of the scores risk groups separeted into low, intermediate and high. The PADUA score is a reliable tool for predicting the risk of complications such as blood loss, and important parameters such as operation time and ischemic period [5]. This can help clinicians in selecting patients suitable for open/laparoscopik/robotic surgery or referring to alternative therapies.

The R.E.N.A.L. nephrometry scoring system , uses the features obtained from contrast-enhanced cross-sectional imaging: $\mathrm{R}$ (radius, maximal diameter in centimeters), E(exophytic/ endophytic properties), $\mathrm{N}$ (nearness to collecting system/renal sinus in millimeters), A (anterior/posterior location), L (location relative to polar lines). This scores defines, tumor complexity: low complexity (nephrometry score $=4-6$ ), moderate complexity (nephrometry score $=7-9$ ), and high complexity (nephrometry score $=10-12$ ) [6]. The R.E.N.A.L. nephrometry scoring system also provides an objective tool of an enhancing renal mass and helps for the optimal surgical approach.

C-Index Method requires a complex geometric calculation use of crosssectional imaging to determine the distance from the tumor center to the center of the kidney [7].

\section{Surgery of Kıdney Cancer}

Surgery is the anchor for curative treatment of RCC, and must be comprise to excise all tumor with an adequate surgical magrin. This excision may include the kidney (radical nephrectomy) or the tumour (partial nephrectomy). Nephrectomy can be performed with open surgical and laparoscopic techniques.Open radical nephrectomy(ORN) which was described by Robon et al in 1969 [8] was the primary treatment method for renal cell carcinoma until 1990 [9]. At first it's decsibed as early ligation of the renal artery and vein, extraction of the kidney outside Gerota's fascia, excision of the ipsilateral adrenal gland, and a complete regional lymphadenectomy from the crus of the diaphragm to the aortic bifurcation. Renal arterial ligation remains an accepted practice but it has been well demonstrated that removal of the ipsilateral adrenal gland is not routinely necessary in the absence of radiographic adrenal enlargement unless the malignant lesion extensively involves the kidney, is locally advanced, or is located

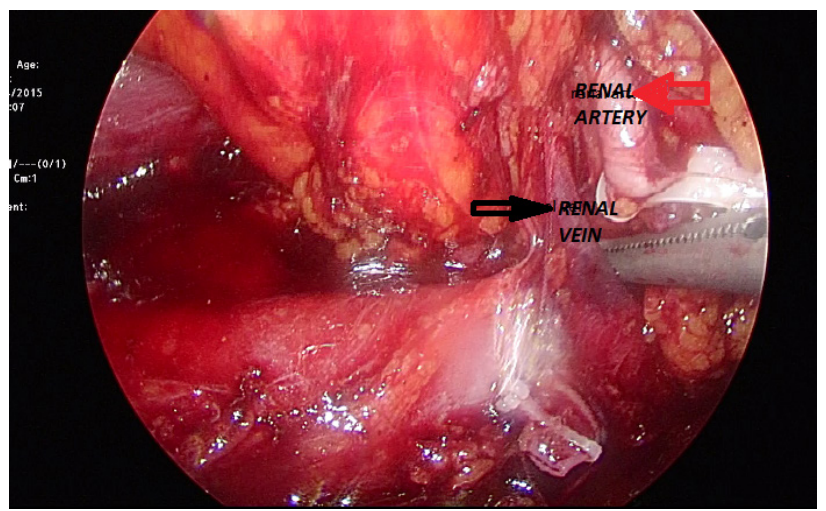

Figure 1. The ureter and psoas majör images at the laparoscopy.
Figure 2. The renal arter and vein images. 
in the upper portion of the kidney immediately adjacent to the adrenal gland [10]. The need for a complete regional in all patients undergoing radical nephrectomy remains controversial. Although lymphadenectomy does not provide any benefit in the majority of RCC cases (mainly TlabN0M0 cases), it remains an important consideration in patients with locally advanced disease (T3-T4) [11]. Routine adrenalectomy and lymphadenectomy are no longer recommended.

Over the last two decades, advances in renal imaging lead increasing of the diagnosis of small renal tumor $(<4 \mathrm{~cm})$ in lower stages [12]. Approximately $75 \%$ of renal masses are less than $4 \mathrm{~cm}$ in size was detected incidentally [13]. By the advances in renal and vascular surgery; partial nephrectomy (PN) is now considered the standard treatment that has superior functional and equivalent oncological outcomes for T1 tumors $(<7 \mathrm{~cm})$ when techniqually feasible [14]. The first case of open partial nephrectomy (OPN) for renal tumor was performed by Czerny in 1887 [15]. The PN became the standard treatment for T1 tumors after the study reported by Von Poppel et al [16]. The guidelines of American Urological Association suggest partial nephrectomy as alternative standard treatment to radical nephrectomy for T1b masses [17], European Association of Urology guidelines recommend partial nephrectomy for kidney tumors larger than $4 \mathrm{~cm}$, whenever technically feasiblen [18].

The indications for partial nephrectomy are bilateral renal tumours, tumour in anatomically or functionally solitary kidney, renal masses in familial and hereditary disease, unilateral mass $<7$ $\mathrm{cm}$ with a normal contralateral kidney and advanced renal cancer [13].

In 1991, Clayman et al [19] performed the first laparoscopic transperitoneal nephrectomy (LTN) and because of advantages in the patient recovery and perioperative morbidity, this technique

Table 1. TNM Classification for Renal Cell Carcinoma (AJCC TNM Staging System, 8th edition, 2017)

\section{Staging}

\section{Primary tumor (T)}

TX

T0

$\mathrm{T} 1$

T1a

$\mathrm{T} 1 \mathrm{~b}$

$\mathrm{T} 2$

$\mathrm{T} 2 \mathrm{a}$

$\mathrm{T} 2 \mathrm{~b}$

$\mathrm{T} 3$

T3a

$\mathrm{T} 3 \mathrm{~b}$

$\mathrm{T} 3 \mathrm{c}$

$\mathrm{T} 4$

Regional lymph nodes (N)

NX

N0

N1

\section{Distant metastasis (M)}

\section{Criteria}

Primary tumor cannot be assessed

No evidence of primary tumor

Tumor $\leq 7 \mathrm{~cm}$ in greatest dimension, limited to the kidney

Tumor $\leq 4.0 \mathrm{~cm}$

Tumor $>4.0 \mathrm{~cm}$ but $\leq 7.0 \mathrm{~cm}$

Tumor $>7.0 \mathrm{~cm}$ in greatest dimension, limited to the kidney

Tumor $>7 \mathrm{~cm}$ but $\leq 10 \mathrm{~cm}$

Tumor $>10 \mathrm{~cm}$, limited to the kidney

Tumor extends to major veins or peri-nephric tissues but not into the ipsilateral adrenal gland and not beyond Gerota fascia

Tumor extends into the renal vein or its segmental branches, or invades the pelvicalyceal system, or invades perirenal and/or renal sinus fat but not beyond Gerota's fascia

Tumor grossly extends into the vena cava below the diaphragm

Tumor grossly extends into the vena cava above the diaphragm or invades the wall of the vena cava Tumor invades beyond Gerota fascia (including contiguous extension into the ipsilateral adrenal gland)

Regional node metastasis cannot be assessed

No regional lymph node zmetastasis

Metastasis in regional lymph node(s)

No distant metastasis

Distant metastasis 


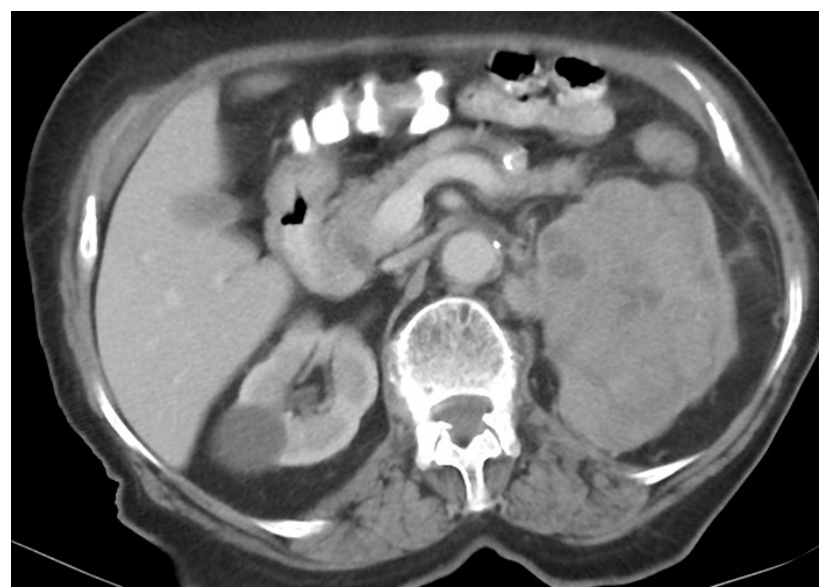

Figure 3. The renal cell carcinoma involving all of the kidney.

has gained worldwide acceptance as a standard treatment for renal cell carcinoma [9]. Laparoscopic radical nephrectomy (LRN) can be done with transperitoneal, hand-assisted transperitoneal and retroperitoneal techniques. Laparoscopic partial nephrectomy (LPN) was first performed by Winfield et al on a patient with lower pole- caliceal diverticulum in 1993 [20]. Unfortunately, early series of LPN revelaed serious urological and nonurological complications lead to reflect the learning curve [21]. Despite a more challenging learning curve it is now accepted as excellent platform in terms of oncologic and surgical principles for kidney tumors.

The patients with competing comorbidities and small masses are applicable for radiofrequency ablation (RFA) or cryoablation as a minimally invasive technique. The most common approach is laparoscopic, although an increasing number of publications report percutaneous route for these techniques [22]. Nevertheless, surgical removal is still considered to be the most significant procedure in the management of renal cell carcinoma.

\section{Laparoscopic Radical Nephrectomy}

After its introduction in 1991 by Clayman et al. [19] LRN offered a minimally invasive alternative to the classical ORN with less wound pain, decreased analgesic requirement and morbidity, more rapid convalescence, and faster return to normal activities [22]. The studies published between 2002 and 2010 showed that long term oncological results of LRN are similar with open surgery [23-

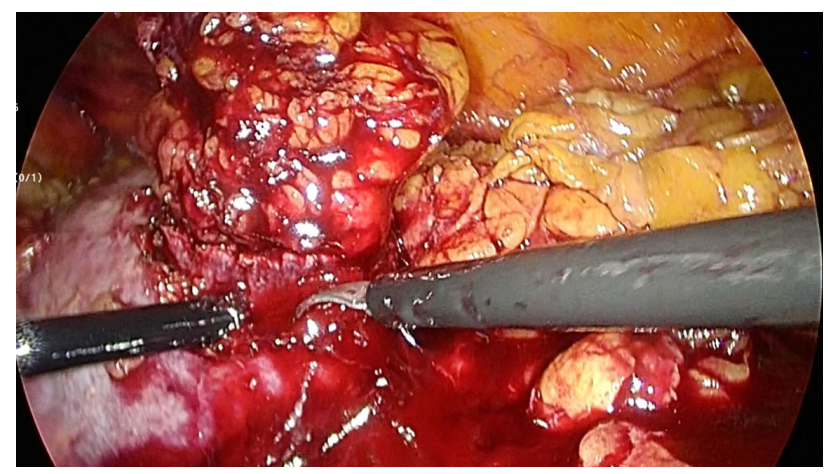

Figure 4. Surgical margin at laparoscopic partial nephrectomy.
25]. A new published meta-analysis; the authors reproted that LRN had better results for cancer-specific mortality and local tumor recurrence than open surgery [9].

LRN had also superior perioperative results including shorter hospital stay, decreased hospitalization, early oral intake, less blood loss, lower blood transfusion rate and better surgical outcomes compared to open surgery. LRN may have techniqual problems for beginners; such as limited working area, adjacent organ involvement, orientation parasitic vessels and specimen removal in patients with large tumor size. The patients should be informed about complications including adjacent organ injury, unrecognized bowel injury and possibility conversion to open surgery.

Prior abdominal surgery may vary the approach between transperitoneal or retroperitoneal and the placement site of trocars. Severe cardiac or pulmonary disease may place the patient at risk for complications due to the pneumoperitoneum, Patients with chronic obstructive pulmonary disease may not be able to compensate for hypercarbia induced by the pneumoperitoneum and may require lower insufflation pressures [26, 27]. Obesity is not a contraindication to laparoscopy but may alter traditional trocar site selection because of the increased distance to the operative area. Anticoagulated patients are managed in cooperation with their primary physician. Patients with thrombocytopenia can receive platelets 30 minutes before the incision to increase their platelet count to greater than $50,000 / \mathrm{ml}$. Additional platelet transfusion should not be necessary in the absence of symptomatic bleeding [28]. Other relative contraindications to laparoscopic renal surgery include abdominal ascites and

pregnancy.

Laparoscopic or hand-assisted laparoscopic applications have become the standard management for radical nephrectomy of T1-T3a renal tumors in adults. LRN can be performed with transperitoneal, retroperitoneal and hand assited transperitoneal approaches.

\section{Transperitoneal Laparoscopic Radical Nephrectomy(TLRN)}

The transperitoneal approach is the basic method used to for laparoscopic surgery. The patient is placed in a modified flank position, with the umbilicus at the edge and the anterior superior iliac spine at the break of the surgical table. The table is broken for suitable working space. After the pneumoperitoneum is established by Veress needle, Hasson open technique or direct insertion of an optical trocar, a $10-12-\mathrm{mm}$ port is placed lateral to the rectus muscle at the level of the umbilicus. Other trocars are inserted under direct vision. While care should be taken to position the trocars in an ideal configuration, this goal is not always achieved [29].

After entering to abdomen,the white line of Toldt is incised from the level of the iliac vessels and the colon is carefully mobilized medially. For left-sided tumors the lienocolic ligament should be incised, while for right-sided tumors, the duodenum is kocherized, and the inferior vena cava and renal vein are skeletonized. Properly mobilisation of the colon makes the psoas muscle visible. The gonadal vessels are extends medially to the psoas muscle. The ureter is usually located just deep to these vessels (Figure 1). The ureter takes us to the lower pole of the kidney. While dissecting renal hilum the artery is divided first, followed by the renal vein with an endovascular stapler or between clips (Figure 2). After lateral fascia attachments are divided, releasing the surgical specimen; the specimen is placed into a lap-sac. And can be removed intact through an incision either from an extended trocar site or Pfannenstiel incision [30].

Portis et al. reported 5 years disease-free survival was $92 \%$ to $91 \%$ for patients treated with laparoscopically versus open surgery 
Table 2. Anatomic Staging for Renal Cell Carcinoma (AJCC TNM Staging System, 8th edition, 2017)

$\begin{array}{ll}\text { Stage } & \text { Stage grouping } \\ \text { I } & \text { T1, N0, M0 } \\ \text { II } & \text { T2, N0, M0 } \\ & \text { T1 or T2, N1, M0 } \\ \text { III } & \text { T3, N0 or N1, M0 } \\ & \text { T4, Any N, M0 } \\ \text { IV } & \text { Any T, Any N, M1 }\end{array}$

[31]. Chan et al. reported similar results of 5 years disease free survival $95 \%$ and $86 \%$ for LRN and open-surgery [32]. Saika et al reported the long-term results of LRN patients. pT1a patients have recurrence free survival rates are $97 \%$ at 5 years and $94 \%$ at 10 years, pT $1 \mathrm{~b}$ patients have $92 \%$ at 5 years, pT $268 \%$ at 5 years [25]. No significant differences in oncological efficacy were found between the laparoscopic and open-surgery groups. It is accepted that laparoscopic radical nephrectomy is a standard treatment modality for patients with $\mathrm{T} 1$ and $\mathrm{T} 2$ renal cell carcinoma $[25,31$, $32,33]$.

\section{Retroperitoneal Laparoscopic Radical Nephrectomy(RLRN)}

The patient is placed as the affected side upwards, preferred in the center of the bed and in the full flank position. The table must be broken maximally for increasing working space. RLRN mimics traditional open surgery in that the kidney is approached without entry into the peritoneal cavity. A $2 \mathrm{~cm}$ skin incision is made below the tip of the 12th rib, the posterior lumbodorsal fascia is incised and entered bluntly with a finger to the retroperitoneal space. With a silastic balloon dilator the working space is created by inflating approximately $800 \mathrm{cc}$ [29]. Second trocar is deployed just lateral to the paraspinous muscles at the costovertebral angle and third trocar can be deployed anterior to the primary access site along the same line defined by the first two trocars [29]. Anatomical orientation is different from the intraperitoneal

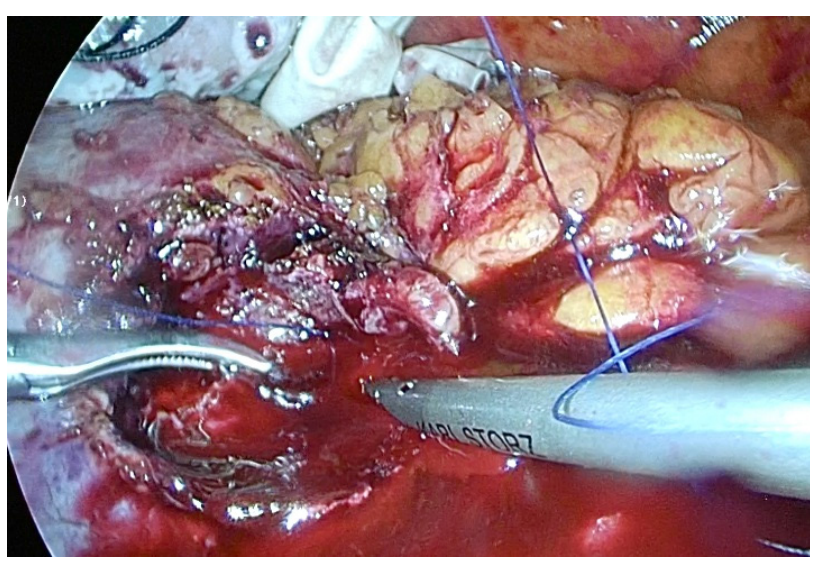

Figure 5. After complete excision of tumor, using sutures for closing renal paranchyma. radical nephrectomy.On the left side, the classic landmarks are the ureter and the left gonadal vein, while on the right side, the classic landmarks are the inferior vena cava and the ureter [30].

The authors found no significant difference for blood loss, hospital stay, oral intake time and pain between TLRN and RLRN [34]. RLRN had a shorter time to renal vascular control, lower complication rate, shorter operation time and hospital stay than the transperitoneal technique. Disadvantages of retroperitoneal approach are small working space, limited landmarks and disorientation. Whereas, some authors prefer the retroperitoneal approach, some others mentioned the advantage of larger working space in transperitoneal nephrectomy; it depends mostly on the surgical experience of the surgeon [33].

\section{Hand-Assisted Laparoscopic Radical Nephrectomy(HALRN)}

Some urologists have adapted a hand-assisted technique for LRN that affords patients the advantages of a laparoscopic procedure and permits the surgeon to use the operating hand for tactile feedback, surgical dissection, and surgical retraction. HALRN is a bridge between laparoscopic and open surgery and may help surgeons without advanced laparoscopic training gain the necessary experience [28]. The patient position is the same as for transperitoneal renal surgery with the umbilicus at the edge of the surgical table for easy movement. HALRN requires a 6- 8-cm incision through a lower quadrant Gibson-type incision or through the lower mid line abdomen for hand-port placement. HALRN may be useful difficult dissection such as infectious processes or prior surgery. For kidney extraction it benefits a larger incision, but disposable hand-port devices increases the cost of the procedure. HALRN might be comparable with open nephrectomy with regard to long-term cancer control [35]. Patients with larger renal mass like shown in Figure 3, $(12 \times 10 \mathrm{~cm}$; covering all the renal parenchym suggesting T3a), can be operated by HALRN.

\section{Laparoscopic Partial Nephrectomy(LPN)}

The fundamentals of LPN just likes the open surgery. Intraoperatively adequate surgical magrin is assessed by either direct vision or laparoscopic ultrasonography (Figure 4). If required, the collecting system can be resected with the surgical specimen to obtain adequate margins and then repaired (Figure 5). LPN is technically difficult surgery, therefore, it was limited to patients with two kidneys, normal renal function and small, exophytic, peripheral tumours in one decade ago [13]. Furthermore, the studies showed that partial nephrectomy can be alternative to radical nephrectomy for renal tumors 
$<7 \mathrm{~cm}$ [36-38]. Now it is recommended at stage T1a, and if it is feasible favoured at stage T1b over radical nephrectomy. LPN has some serious complications including haemorrhage, urine leaks and non-urological complicaitons such as pneumothorax or tension pneumothorax, pulmonary edema and pneumonia [13]. Ischaemia time is important for acute and chronic kidney injury risk [39]. While cold ischaemia is better than warm and longer than 25 minutes of warm ischaemia time increases the risk of renal injury. Cold ischaemia is techniqually very difficult in LPN cases, so complex kidney tumors which are needed long ischemia time can be treated with open surgical approaches. Several techniques were described including renal hypothermia, early unclamping, selective renal arterial clamping, parenchymal compression plus clamping and off clamp [40]. The complications rate was decreased with experience and contemporary technical developments (haemostatic agents or bolsters) [13]. Gill et al [41] had high experience for laparoscopy and investigated 1800 patients who underwent partial nephrectomy and reported that LPN had advantages for operative time, blood loss and hospital stay when compared open surgery. The conversion to radical nephrectomy risk was higher in laparoscopic than open technique. The studies revealed that LPN had comparable overall survival, cancer specific survival and progression free survival when compared to open partial nephrectomy [41, 42].

\section{Robot-assisted partial nephrectomy(RAPN)}

Although the benefits of the LPN, it is a more challenging procedure for the surgeon because of its reconstructive nature and the increased risk of intraoperative bleeding and postoperative complications $[17,43]$. Studies have shown LPN to be a difficult procedure with a lengthy learning curve and requires extensive repetition achieve the type of perioperative outcomes [43]. RAPN has emerged as an alternative to LPN for removal of renal tumors for shortening the learning curve associated with laparoscopy. The benefits are a greater range of motion, greater manual dexterity and flexibility, optically magnified imaging, enhanced visualization, precision of control and tremor reduction resulting resulting in reduced total operation time and less amount of experience required by the surgeon [43-46]. In their study Omidele et al. showed that RAPN is a safe, effective treatment modality for small renal masses, the outcomes are better than LPN and is a technically easier procedure to master. This goal can be reached after $>61-90$ cases at a rate of 20 cases per year [43]. "Trifecta" is a statement used in radical prostatectomy and now Hung et al [47, 48] introduced the outcomes of partial nephrectomy as; providing negative surgical margins, minimal renal function decrease, and absence of complications in the same patient. As renal injury is directly proportional with warm ischemia time (WIT), after the first introducing; some authors defined as no complications, negative surgical margins, and WIT $\leq 25$ minutes [48-50]. K1m et al. reported that rate of achievement of Trifecta of T1a, T1b renal mass was significantly higher in Tla group (65.3\% vs $43.3 \%)$ and pointing out tumor size and operation time were significant predictive factors of Trifecta achievement [49].

Controversially Porpiglia et al. reported Trifecta outcomes of robot-assisted surgical T1b patients as $69.5 \%$ and Tufek et al. reported Trifecta outcomes $58 \%[48,50]$. Their conclusion is RAPN for T1b renal masses may be safely performed in experienced hands.Although the benefits of the LPN, it is a more challenging procedure for the surgeon because of its reconstructive nature and the increased risk of intraoperative bleeding and postoperative complications $[17,43]$. Studies have shown LPN to be a difficult procedure with a lengthy learning curve and requires extensive repetition achieve the type of perioperative outcomes [43]. RAPN has emerged as an alternative to LPN for removal of renal tumors for shortening the learning curve associated with laparoscopy. The benefits are a greater range of motion, greater manual dexterity and flexibility, optically magnified imaging, enhanced visualization, precision of control and tremor reduction resulting resulting in reduced total operation time and less amount of experience required by the surgeon [43-46]. In their study Omidele et al. showed that RAPN is a safe, effective treatment modality for small renal masses, the outcomes are better than LPN and is a technically easier procedure to master. This goal can be reached after $>61-90$ cases at a rate of 20 cases per year [43]. "Trifecta" is a statement used in radical prostatectomy and now Hung et al [47, 48] introduced the outcomes of partial nephrectomy as; providing negative surgical margins, minimal renal function decrease, and absence of complications in the same patient. As renal injury is directly proportional with warm ischemia time (WIT), after the first introducing; some authors defined as no complications, negative surgical margins, and WIT $\leq 25$ minutes [48-50]. Kim et al. reported that rate of achievement of Trifecta of T1a, T1b renal mass was significantly higher in Tla group $(65.3 \%$ vs $43.3 \%$ ) and pointing out tumor size and operation time were significant predictive factors of Trifecta achievement [49].

Controversially Porpiglia et al. reported Trifecta outcomes of robot-assisted surgical $\mathrm{T} 1 \mathrm{~b}$ patients as $69.5 \%$ and Tufek et al. reported Trifecta outcomes 58\% [48, 50]. Their conclusion is RAPN for T1b renal masses may be safely performed in experienced hands.

\section{Novel Techniques under Laparoscopic Surgery}

Elderly patients with small RCCs, accompanying comorbidities and those with severe renal dysfunction, are not suitable for surgical excision. Many of these patients are good candidates for thermal ablation, either by radiofrequency ablation (RFA) or by cryoablation [22]. During RFA, a high frequency alternating current (350 to $500 \mathrm{kHz}$ ) flows from the uninsulated tip of an electrode into the tissue. Ionic motility is produced in the tissue by the alternating current. This motility, results in frictional heating in the tissue about the electrode [51-53]. Cell death occurs within minutes of exposure to temperatures at or above $50^{\circ} \mathrm{C}$. Temperatures in the $50-100^{\circ} \mathrm{C}$ range are maintained homogeneously throughout the target area for optimal therapy [54]. Cryoablation directly kills tumor cells at a temperature of $-40^{\circ} \mathrm{C}$ by causing osmotic dehydration that damages organelles, and the cell membrane and by causing intracellular ice formation that supercools the cytoplasmic contents $[55,56]$. This typically occurs when the ice ball extends $0.5-1 \mathrm{~cm}$ beyond the tumor margins [57]. Posterior or lateral tumors are accessible percutaneously under CT or MRI guidance. Tumors that are anterior, medial or those close to the renal hilum or ureter require laparoscopic approach. In the laparoscopic RFA, initial electrode placement is performed under laparoscopic ultrasound guidance for the tumor and its depth [22]. The most common cryoablation approach is laparoscopic, although an increasing number of publications report percutaneous route. Either cryoablation or laparoscopic RFA can be performed transperitoneal or retroperitoneal approach. The only variable is localisation of the tumor. Treatment has traditionally been considered successful on the basis of two findings on imaging studies, absence of enhancement and involution of the tumor. Minimally invasive treatment and causing less morbidity and renal dysfunction than other nefron sparing surgeries are the advantages [22]. The lack of the long term follow up and high costs of the procedure are the disadvantages. Recurrence after prior partial nephrectomy and elderly patients competing comorbidities with a small renal mass, are good candidates for thermal ablation therapies. 


\section{Conclusion}

In conclusion, laparoscopic approaches increased in the last two decades because of less pain and earlier recovery to full convalescence and normal activity. In addition to these benefits; long-term cancer control of LRN is similar to that of open surgery. So it had become a gold standard treatment modality for patients with T1 to T3a RCC. Patients with history of intraperitoneal surgeries, RLRN can be considered as a suitable procedure. Despite novel technological advancements in robotics and ablative therapies, LPN remains a valid alternative to OPN with comparable cancer survival and a viable modality. Current developments for instrumental devices and surgical experience will increase the laparoscopic surgery success for renal cell carcinomas.

\section{Ethical policy}

No research involving experimentation on human or animal subjects was conducted.

\section{Author contributions}

All authors contribute equally for writing this article.

\section{Competing interests}

None

\section{Ethical statement}

This article has no ethical approval.

\section{References}

1. Seveso M, Grizzi F,Bozzini G, Mandressi A, Guazzoni G, Taverna G: Open partial nephrectomy: ancient art or currently available technique? Int Urol Nephrol 2015, 47(12): 1923-1932.

2. Çalışkan S, Koca O, Akyüz M, Karaman MI: Benign renal tumors who underwent radical or partial nephrectomy. The New Journal of Urology 2014, 9(1): 34-37.

3. Smith ZL: Current Status of Minimally Invasive Surgery for Renal Cell Carcinoma. Curr Urol Rep 2016, 17: 43.

4. Chang X, Liu T, Zhang F, Qian C, Ji C, Zhao X, Liu G, Guo H: The Comparison of R.E.N.A.L., PADUA and Centrality Index Score in Predicting Perioperative Outcomes and Complications after Laparoscopic Radio Frequency Ablation of Renal Tumors. J Urol 2015, 194(4): 897-902.

5. Waldert M, Waalkes S, Klatte T, Kuczyk MA, Weibl P, Schüller G, Merseburger AS, Remzi M: External validation of the preoperative anatomical classification for prediction of complications related to nephron-sparing surgery. World J Urol 2010, 28(4): 531535 .

6. Parsons RB, Canter D, Kutikov A, Uzzo RG: RENAL nephrometry scoring system: the radiologist's perspective. AJR Am J Roentgenol 2012, 199(3): 355-359.

7. Simmons MN, Ching CB, Samplaski MK, Park CH, Gill IS: Kidney tumor location measurement using the $\mathrm{C}$ index method. J Urol 2010, 183: 1708-1713.

8. Robson CJ, Churchill BM, Anderson W: The results of radical nephrectomy for renal cell carcinoma. J Urol 1969, 101: 297-301.

9. Liu G, Ma Y, Wang S, Han X, Gao D: Laparoscopic Versus Open Radical Nephrectomy for Renal Cell Carcinoma:a Systematic Review and Meta-Analysis. Translational Oncology 2017, 10: 501510 .

10. Siemer S, Lehmann J, Kamradt J, Loch T, Remberger K, Humke U, Ziegler M, Stöckle M: Adrenal metastases in 1635 patients with renal cell carcinoma: Outcome and indication for adrenalectomy. J Urol 2004, 171: 2155-2159.

11. Capitanio U, Becker F, Blute ML, Mulders P, Patard JJ, Russo P, Studer UE, Van Poppel H: Lymph node dissection in renal cell carcinoma. Eur Urol 2011, 60(6): 1212-1220.

12. Schurhamer B, Littlejohn N, Eltahawy E, Davis R: Partial nephrectomy in the Overweight Patient:an Overview. Curr Urol Rep 2016, 17(1): 2.

13. Leslie S, Goh AC, Gill IS: Partial nephrectomy-contemporary indications, techniques and outcomes. Nat Rev Urol 2013, 10(5): 275283.

14. Raison N, Doeuk N, Malthouse T, Kasivisvanathan V, Lam W, Challacombe B: Challenging situations in partial nephrectomy. Int J Surg 2016, 36: 568-573.

15. Herr HW: A History of Partial Nephrectomy For Renal Tumors. J Urol 2005, 173: 705-708.

16. Van Poppel H, Da Pozzo L, Albrecht W, Matveev V, Bono A, Borkowski A Colombel M, Klotz L, Skinner E, Keane T et al: A prospective, randomised EORTC intergroup phase 3 study comparing the oncologic outcome of elective nephron-sparing surgery and radical nephrectomy for low-stage renal cell carcinoma. Eur Urol 2011, 59: 543-552.

17. Campbell SC, Novick AC, Belldegrun A, Blute ML, Chow GK, Derweesh IH, Faraday MM, Kaouk JH, Leveillee RJ, Matin SF et al: Guideline for management of the clinical T1 renal mass. J Urol 2009, 182: 1271-1279.

18. Ljungberg B, Bensalah K, Canfield S, Dabestani S, Hofmann F, Hora M, Kuczyk MA, Lam T, Marconi L, Merseburger AS et al: EAU guidelines on renal cell carcinoma: 2014 update. Eur Urol 2015, 67: 913-924.

19. Clayman RV, Kavoussi LR, Soper NJ, Dierks SM, Meretyk S, Darcy MD, Roemer FD, Pingleton ED, Thomson PG, Long SR: Laparoscopic nephrectomy: initial case report. J Urol 1991, 146: 278282.

20. Winfield HN1, Donovan JF, Godet AS, Clayman RV: Laparoscopic partial nephrectomy: initial case report for benign disease. J Endourol. 1993, 7(6): 521-526.

21. Ramani AP, Desai MM, Steinberg AP, Ng CS, Abreu SC, Kaouk JH, Finelli A, Novick AC, Gill IS: Complications of laparoscopic partial nephrectomy in 200 cases. J Urol 2005, 173: 42-47.

22. SC Campbell, BI Rini: Renal cell carcinoma Clinical Management. Humana Press 2013, 155.

23. Luo JH, Zhou FJ, Xie D, Zhang ZL, Liao B, Zhao HW, Dai YP, Chen LW, Chen W: Analysis of long-term survival in patients with localized renal cell carcinoma: laparoscopic versus open radical nephrectomy. World J Urol 2010, 28: 289-293.

24. Portis AJ, Yan Y, Landman J, Chen C, Barrett PH, Fentie DD, Ono Y, McDougall EM, Clayman RV: Long-term followup after laparoscopic radical nephrectomy. J Urol 2002, 167: 1257-1262.

25. Saika, T, Ono, Y, Hattori R, Gotoh M, Kamihira O,Yoshikawa Y, Yoshino Y, Ohshima S: Long term outcome of laparoscopic radical nephrectomy for pathological T1 renal cell cancer. Urology 2003, 62: 1018-1023.

26. Lew JKL, Gin T, Oh TE: Anaesthetic problems during laparoscopic cholecystectomy. Anaesth Intens Care 1992, 20: 91.

27. W o l f J S : $\mathrm{P}$ a $\mathrm{t}$ h o Effects of prolonged laparoscopic operation. Sem Surg Oncol 1996, 12: 86-95.

28. Wein AJ, Kavoussi LR, Novick AC, Partin AW, Peters CA: Campbell-Walsh Urology, 9th Edition. 2007 Saunders, An Imprint of Elsevier. Laparoscopic surgery of the kidney.

29. Collins S, Lehman DS, McDougall EM, Clayman RV, Landman J: AUA BLUS Handbook of Laparoscopic and Robotic Fundamentals.

30. Al-Qudah HS, Rodriguez AR, Sexton WJ : Laparoscopic management of kidney cancer: updated review. Cancer Control. 2007, 14(3): 218-230. 
31. Portis, A J, Yan Y, Landman J, Chen C, Barrett PH, Fentie DD, Ono Y, McDougall EM, Clayman RV: Long-term follow-up after laparoscopic radical nephrectomy. J. Urol 2002, 167: 1257-1262.

32. Chan DY, Cadeddu JA, Jarrett TW, Marshall FF, Kavoussi LR: Laparoscopic radical nephrectomy: cancer control for renal cell carcinoma. J. Urol 2001, 166: 2095-2100.

33. Eskicorapci SY, Teber D, Schulze M, Ates M, Stock C, Rassweiler JJ: Laparoscopic radical nephrectomy: the new gold standard surgical treatment for localized renal cell carcinoma. Scientific World Journal 2007, 9(7): 825-836.

34. Fan X, Xu K, Lin T, Liu H, Yin Z, Dong W, Huang H, Huang J: Comparison of transperitoneal and retroperitoneal laparoscopic nephrectomy for renal cell carcinoma: a systematic review and metaanalysis. BJU Int 2013, 111(4): 611-621.

35. Hongo F, Kawauchi A, Ueda T, Fujihara A, Naitoh Y, Nakamura T, Naya Y, Kamoi K, Okihara K, Miki T: Long-term outcome of hand-assisted laparoscopic radical nephrectomy for T1 renal cell carcinoma. Int J Urol 2014, 21(11): 1093-1096.

36. Long CJ, Canter DJ, Kutikov A, Li T, Simhan J, Smaldone M, Teper E, Viterbo R, Boorjian SA, Chen DY et al: Partial nephrectomy for renal masses $\geq 7 \mathrm{~cm}$ :technical, oncological and functional outcomes. BJU Int 2012, 109: 1450-1456.

37. Becker F, Roos FC, Janssen M, Brenner W, Hampel C, SiemerS, Thüroff JW, Stöckle M: Short-term functional and oncologic outcomes of nephron-sparing surgery for renal tumours $\geq 7 \mathrm{~cm}$. Eur Urol 2011, 59: 931-937.

38. Tsivian M, Tsivian E, Stanevsky Y, Bass R, Sidi AA, Tsivian A: Laparoscopic partial nephrectomy for tumors $7 \mathrm{~cm}$ and above. Perioperative outcomes. IBJU 2017, 43: 857-862.

39. Anastasiadis E, O'Brien T, Fernando: Open partial nephrectomy in renal cell cancer - Essential or obsolete? Int J Surg 2016, 36: 541-547.

40. Ng AM, Shah PH, Kavoussi LR: Laparoscopic Partial Nephrectomy:A Narrative Review and Comparison with Open and Robotic Partial Nephrectomy. J Endourol 2017, 31(10): 976-984.

41. Gill IS, Kavoussi LR, Lane BR, Blute ML, Babineau D, Colombo JR Jr, Frank I, Permpongkosol S, Weight CJ, Kaouk JH et al: Comparison of 1,800 laparoscopic and open partial nephrectomies for single renal tumors. J Urol 2007, 178: 41-46.

42. Marszalek M, Meixl H, Polajnar M, Rauchenwald M,Jeschke K, Madersbacher S: Laparoscopic and open partial nephrectomy:a matched-pair comparison of 200 patients.Eur Urol 2009, 55: 11711178 .

43. Omidele OO, Davoudzadeh N, Palese M: Trifecta Outcomes to Assess Learning Curve of Robotic Partial Nephrectomy. JSLS 2018, 22(1).

44. Benway BM, Wang AJ, Cabello JM, Bhayani SB: Robotic partial nephrectomy with sliding-clip renorrhaphy: technique and outcomes. Eur Urol 2009, 55: 592-599.

45. Cha EK, Lee DJ, Del Pizzo JJ: Current status of robotic partial nephrectomy (RPN). BJU Int 2011, 108: 935-941.

46. Mottrie A, De Naeyer G, Schatteman P, Carpentier P, Sangalli M, Ficarra V: Impact of the learning curve on perioperative outcomes in patients who underwent robotic partial nephrectomy for parenchymal renal tumours. Eur Urol 2010, 58: 127-132.

47. Hung AJ, Cai J, Simmons MN, Gill IS: "Trifecta" in partial nephrectomy. J Urol 2013, 189: 36-42.

48. Tufek I, Mourmouris P, Doganca T, Obek C, Argun OB, Tuna MB, Keskin MS, Kural AR: Robot-Assisted Partial Nephrectomy for T1b Tumors: Strict Trifecta Outcomes. JSLS 2017; 21(1).

49. Kim DK, Kim LHC, Raheem AA, Shin TY, Alabdulaali I, Yoon YE, Han WK, Rha KH: Comparison of trifecta and pentafecta outcomes between T1a and T1b renal masses following robotassisted partial nephrectomy (RAPN) with minimum one year follow up: can RAPN for T1b renal masses be feasible? PLoS One. 2016, 11: e 0151738.
50. Porpiglia F, Mari A, Bertolo R, Antonelli A, Bianchi G, Fidanza F, Fiori C, Furlan M, Morgia G, Novara G et al: Partial nephrectomy in clinicalT1b renal tumors: multicenter comparative study of open, laparoscopic, and robot-assisted approach (the RECORd Project). Urology 2016, 89: 45-51.

51. Organ L: Electrophysiologic principles of radiofrequency lesion making. Applied Neurophysiology 1976, 39: 69-76.

52. McGahan J, Browning P, Brock J: Hepatic ablation with use of radiofrequency electrocautery. Invest Radiol 1990, 25: 267-270.

53. Patterson EJ, Scudamore C, Owen DA, et al: Radiofrequency ablation of porcine liver invivo: effects of blood flow and treatment time on lesion size. Ann Surg 1998, 227: 559-565.

54. Goldberg SN, Gazelle GS, Mueller PR: Thermal ablation therapy for focal malignancy: a unified approach to underlying principles, techniques, and diagnostic imaging guidance. Am J Roentgenol 2000, 174(2): 323-31.

55. Hoffmann NE, Bischof JC: The cryobiology of cryosurgical injury. Urology 2002, 60 (2 Suppl 1): 40-49.

56. Daum PS, Bowers Jr WD, Tejada J, Hamlet MP: Vascular casts demonstrate microcirculatory insufficiency in acute frostbite. Cryobiology 1987, 24(1): 65-73.

57. Finelli A, Rewcastle JC, Jewett MA: Cryotherapy and radiofrequency ablation: pathophysiologic basis and laboratory studies. Curr Opin Urol 2003, 13(3): 187-191. 